\title{
Partner profile of pregnant women who have obstetric prenatal high risk in a university hospital south of Brazil
}

\author{
Gisele Perin Guimarães ${ }^{1,2}$, Jussara Gue Martini, ${ }^{3,4,5}$ \\ ${ }^{1}$ Clinical Nurse Neonatology Service of the Regional Hospital of St. Joseph, São José, Brazil \\ ${ }^{2}$ Internment Facility Screening Obstetrical and Gynecological Hospital of the Federal University of Santa Catarina, Florianópolis, \\ Brazil \\ ${ }^{3}$ Department of Nursing and the Graduate Program in Nursing at UFSC, Florianópolis, Brazil \\ ${ }^{4}$ Graduate Program in Respiratory Sciences, Federal University of Rio Grande do Sul, Porto Alegre, Brazil \\ ${ }^{5}$ Center for Health Research, Researcher Group Research in Nursing and Health Education and IEG, Florianópolis, Brazil \\ Email: giseperin@yahoo.com.br, jussarague@gmail.com
}

Received 23 September 2013; revised 20 October 2013; accepted 27 October 2013

Copyright @ 2013 Gisele Perin Guimarães, Jussara Gue Martini. This is an open access article distributed under the Creative Commons Attribution License, which permits unrestricted use, distribution, and reproduction in any medium, provided the original work is properly cited.

\begin{abstract}
This study aimed to relate the social and obstetric risk factors presented by pregnant women who underwent high risk prenatal in a southern Brazil hospital unit. This is a quantitative research. The data collection was conducted from January to September 2012, where 12 high-risk pregnancies and nine companions with diversified social and obstetric conditions were seen. The analysis was by simple statistics. Pregnant women social profile results indicated that predominant age group was 31 to 40 years old; all had some degree of education; $84 \%$ Catholic; $75 \%$ of pregnant women were accompanied by someone of their choice during high risk prenatal care; and 50\% of the choices were for her spouse; half of these pregnant women have a professional occupation. Obstetrics findings demonstrated that the majority of women were not planning on the pregnancy, only $17 \%$ started prenatal care in the first trimester, $42 \%$ had already presented risk in previous pregnancy, $58 \%$ of women were classified as high risk due to fetal abnormalities. Given these findings, it is clear that high-risk pregnancy as a period involving several factors, including social and obstetric that, when connected, can compromise the process of gestating for both the mother and the fetus.
\end{abstract}

Keywords: Pregnancy; Prenatal Care; High Risk; Nursing

\section{INTRODUCTION}

Pregnancy is considered as a physiological event in a couple's life, with a period of evolution, mostly uneventful, surrounded by sensations that generate pleasure and expectations in the months that follow until the ending weeks of gestation. However, this period considered physiologic in women's lives, it is often modified as a result of certain conditions, which triggers specific characteristics that may evolve unfavorably, representing both maternal and fetal risks, with the possibility to admission at a hospital.

Women who experience a pregnancy outside the normal range and that are perceived in a health-disease process are called "high risk pregnancies" [1].

The maternal and fetal risks are not only related to obstetric factors of the current pregnancy, but also external factors that aggregate unfavorable situations to a favorable evolution of the pregnancy, those directly related to social conditions, and history of previous pregnancies.

Another factor that must be taken into consideration is the high number of pregnant teens in our midst, and that has been associated with an increased frequency of adverse obstetric outcomes such as low birth weight, premature delivery, maternal death and perinatal mortality, preeclampsia and cesarean birth, among others. Not that these are classified as high risk, but the possibility of becoming in the course of pregnancy is higher when compared with pregnant women of other age groups [2].

Therefore, this article aims to understand the social and obstetric profile of pregnant women who underwent prenatal high risk in a hospital in southern Brazil.

The importance of identifying the social and obstetric profile of pregnant women helps promote a deeper understanding of the family contexts advantages and difficulties and its relationship, as well as, the risk that rated 
the mother as high risk. Through this social and obstetric information the relationship between subject and researcher gets closer.

\section{METHODOLOGY}

It is a quantitative research carried out in public training hospital in southern Brazil, where the study subjects, 12 high-risk pregnancies and nine companions, were undergoing prenatal care. Data collection began after the subjects were aware of the objectives, intentions and modes of participation, and agreed to participate in the study.

It was not determined a minimum number of participants. The only stipulation was related to a timeframe of six months, which determined that the period to accept new mothers would be from January through June 2012, being this, the exclusion criterion. After ending these months, prenatal care resumed for those who were already in the process of health education, lasting until September when all had finished the reflective processes.

Thus, the sample size $(n=12)$ was set intentionally selecting the elements that compose the inclusion and exclusion criteria, i.e. be high risk pregnancies and interest in participating in the study.

When performing Nursing Consultation (NC), it was necessary to have a better understanding of the social and obstetric' s situation of every high risk pregnant woman accompanied by their companions during their prenatal care. This process proportionated us a better visualization of the main factors related in such special moment of the pregnancy.

At the first stage of the NC, which was carried out individually with the high-risk pregnant women and their companions, is the time when initial dialogue was established in search of validation of the social and obstetric data obtained from their medical records.

Social data collected was: age, education, religion, profession/occupation, marital status and companion of choice. Whereas the obstetric approached parity, for example, the number of pregnancies experienced, whether or not that's a planned pregnancy, risk classification, diagnosis and if there was the need for hospitalization in the current pregnancy.

After being extracted information from medical records, the registry of this data was entered in a field diary and later transferred to an Excel spreadsheet, for simplified tabulation. Data analysis was done using on simple statistics method, enabling a reduction in terms of the sample, representatively without loss characteristics.

Ethical principles established by Resolution 196/96 of the National Health Council [3] and the principles of the Code of Professional Ethics to standardize the investigative activities were respected. Project was submitted to UFSC's (Universidad Federal de Santa Catarina) Ethics
Committee on Human Research, with assent under No. 2257/11, Certificate of Appreciation for Ethics Presentation No. 448412.

\section{RESULTS}

Social and obstetric conditions were varied, thus to better understand the findings of this study, data will be presented separately. First will be social findings and later obstetric events.

Age range of women who experienced high-risk pregnancy $(n=12)$ ranged between 13 and 40 years $(n=5$, $42 \%$ ), of age with predominance (Table 1) for pregnant women between 31 and 40 years old. These assertions is

Table 1. Social profile of pregnant women who received prenatal care in high-risk HU/UFSC-2012.

\begin{tabular}{|c|c|c|}
\hline Profile & $n$ & $\%$ \\
\hline \multicolumn{3}{|l|}{ Ages } \\
\hline $13-19$ years & 3 & 25 \\
\hline 20 - 30 years & 4 & 33 \\
\hline 31 - 40 years & 5 & 42 \\
\hline Total & 12 & 100 \\
\hline \multicolumn{3}{|l|}{ Schooling } \\
\hline High school graduate & 06 & 50 \\
\hline Incomplete secondary education & 06 & 50 \\
\hline Total & 12 & 100 \\
\hline \multicolumn{3}{|l|}{ Religion } \\
\hline Catholic & 10 & 84 \\
\hline Spiritualist & 01 & 8 \\
\hline No religion & 01 & 8 \\
\hline Total & 12 & 100 \\
\hline \multicolumn{3}{|l|}{ Companion } \\
\hline Partner & 06 & 50 \\
\hline Other & 03 & 25 \\
\hline Unaccompanied & 03 & 25 \\
\hline Total & 12 & 100 \\
\hline \multicolumn{3}{|l|}{ Marital status } \\
\hline Stable Union & 07 & 58 \\
\hline Maiden & 04 & 34 \\
\hline Separate & 01 & 8 \\
\hline Total & 12 & 100 \\
\hline \multicolumn{3}{|l|}{ Occupation/profession } \\
\hline Unemployed & 06 & 50 \\
\hline With occupancy & 06 & 50 \\
\hline Total & 12 & 100 \\
\hline
\end{tabular}


in line with results presented by the Ministry of Health [4] highlighting Southern Brazil as the largest proportion of births alive in this age group, whereas the Northern region presents the highest rates of high-risk pregnancies in teens.

The lower age group of women who underwent high risk prenatal in this study was adolescents $(n=3,25 \%)$. Age range considered for teenagers in this study was 13 through 19 years old. This is taking into account the minimum age advocated by Law 8069 of July 13, 1990, which is provided for in the Child and Adolescent Statute. Teen is a person who is between the age of twelve and eighteen years of age. World Health Organization (WHO) adopts the rage between 15 and 19 years [5] for teens.

It was observed that the pregnant women in this study were all literate ( $n=12,100 \%)$, varying only in the level of education, being 50\% high school graduate, and 50\% incomplete secondary education. The fact that these women had a certain degree of education that provided not only practical, visual and life knowledge, but also written words and knowledge exchange during the process of reflection-action-reflection. Some even had read about the risk they were experiencing, and sought for information in the virtual universe of the internet or through people who reported their personal experiences of pregnancy on their blogs, a space on the internet organized in reverse chronological order, focusing on a particular theme, which can be written by a variable number of people who share their personal experiences and can post pictures, text, etc.

However, despite early adoption by the pregnant women of electronic media search for knowledge related to their situation, many readings came distorted, generating higher anxiety levels in them and their companions and increasing emotional instability, requiring constant back and forth to bring them to their reality and closer to the context in which they were living.

Religion, predominating Catholicism (84\%), was something strongly emphasized by the pregnant women, which in conjunction with prenatal care provided comfort, motivation and strength to continue the journey of risky pregnancy. Having faith was the base to keeping them strong and to facing obstacles, besides the strong presence of their companion, which provided greater security in times of difficulty, of expectations and also of happiness.

The choice of companions by the pregnant women during prenatal care was varied. Most women 50\% $(n=6)$ were accompanied by their partners. Other choices of companions were the mother and sister-in-law/Godmother. It stood up the fact that some women $25 \%$ did not have a companion, having to face the difficulties of the high-risk pregnancy without any support, whether from family, friends or someone who they could share their feelings with and encourage a dialogic relationship during the prenatal care assistance meetings.

An important fact that should be noted is the marital status of the 12 pregnant women being followed. Most women had a companion through a domestic union (stable union-Brazilian regulation) 58\% $(n=7)$, allowing for the sharing of moments experienced during the pregnancy. This study had a significant number of unmarried pregnant women, a total of $34 \%(n=4)$.

The constitution of the family income is exercised with balance by the companion, considering that $50 \%$ of pregnant women did not any realize profit-making activities, devoting most of their time to domestic activities. On the other hand, the other $50 \%$ of women from this study had a professional occupation, such as: cleaning ladies; maid; beautician; seamstress, bartender and operator. Beside these activities, they still took care of their home by performing domestic activities and, some, also adopted the role of breadwinner, denoting multiple working shifts.

The results presented so far allowed for a view of the pregnant women's social profile, focus of this study; however, this is not enough to glimpse, in a global scale, the high-risk pregnancy. For that, we present the obstetric profile, trying to correlate the social and obstetric factors that pregnant women underwent during the high-risk prenatal care which allows us to do broader and more appropriate critical analysis.

Obstetric findings reflect the women's profile since the first moment, being that most of these women said they had not planned for the pregnancy. Only some had planned with their companions when to get pregnant. The fact majority had not planned for the pregnancy may justify the beginning of their prenatal care assistance only in the second or third trimester of the pregnancy.

With respect to the parity of the women (Table 2), there was a certain proximity between first pregnancy, those who a generating their first child and second pregnancy. In greater number $(n=5,42 \%)$ it was the group of women that had had three or more pregnancies, which are classified as multigravida.

Previous history of the studied pregnant women shows that the minority of these women had risk situations in some of their previous pregnancies, corresponding to $17 \%$. Most women received low-risk prenatal care at their local Basic Health Units-BHU, in contrast with the current pregnancy where they were classified as high-risk pregnancies and requiring to perform prenatal at hospital of reference for such assistance.

After these pregnant women were considered of highrisk and being monitored by the specialized prenatal care, it was observed that the majority of these high risk pregnant women 92\% $(n=11)$ displayed a serene and uneventful pregnancy, with no need for hospitalization for 
Table 2. Profile of women who underwent obstetric prenatal care for high-risk HU/UFSC-2012.

\begin{tabular}{|c|c|c|}
\hline & $\mathbf{n}$ & $\%$ \\
\hline \multicolumn{3}{|l|}{ Home assistance prenatal } \\
\hline $1^{\circ}$ trimester & 02 & 17 \\
\hline $2^{\circ}$ trimester & 06 & 50 \\
\hline $3^{\circ}$ trimester & 04 & 33 \\
\hline Total & 12 & 100 \\
\hline \multicolumn{3}{|l|}{ Parity } \\
\hline First pregnancy & 03 & 25 \\
\hline Second pregnancy & 04 & 33 \\
\hline Three or more pregnancies & 05 & 42 \\
\hline Total & 12 & 100 \\
\hline \multicolumn{3}{|l|}{ Risk situation in previous pregnancy } \\
\hline Yes & 02 & 17 \\
\hline No & 07 & 58 \\
\hline Not applicable (first pregnancy) & 03 & 25 \\
\hline Total & 12 & 100 \\
\hline \multicolumn{3}{|l|}{ Hospitalization this pregnancy } \\
\hline Yes & 01 & 8 \\
\hline No & 11 & 92 \\
\hline Total & 12 & 100 \\
\hline
\end{tabular}

reasons related to the pregnancy. However, it is noteworthy that three pregnant women were first pregnancy and not considered in relation to the experience of previous pregnancies.

Women studied, in addition to being classified as high risk within the prenatal care assistance, were also directed based on the risk type (Table 3 ). This could be maternal risk, fetal risk and maternal-fetal risk. When relating the type of risk, we've realized that most of the women $58 \%$ were performing prenatal risk due to fetal risk, and a smaller proportion ( $n=5,42 \%)$ was related to maternal-fetal risk. None of the studied women presented maternal risk exclusively.

Such risk ratings were determined from the clinical diagnoses (Table 4) collected during prenatal care, which guided the approach and dialogic processes during all interactions, favoring the overcoming of needs presented by each of the women and their companions.

The way pregnant women faced these situations of risk and their unborn was favored not only by specialized prenatal care, which targeted their needs, but also, and with the same value, by the possibility of having along this journey of choosing the companion who was significant and who could support, encourage, understand their feelings and share the whole process of reflection-
Table 3. Risk of obstetric pregnant women who underwent prenatal high risk in HU/UFSC-2012.

\begin{tabular}{ccc}
\hline Risks obstetric & $\boldsymbol{n}$ & $\mathbf{\%}$ \\
\hline Fetal & 07 & 58 \\
Maternal - fetal & 05 & 42 \\
Maternal & 00 & - \\
Total & $\mathbf{1 2}$ & $\mathbf{1 0 0}$
\end{tabular}

Table 4. Diagnostic risk of pregnant women who received prenatal care in high-risk HU/UFSC-2012.

\begin{tabular}{cc}
\hline & Diagnostic risk obstetric \\
\hline Maternalfetal & Fetal \\
Sickle cell anemia & Diaphragmatic hernia \\
Adolescence & Dextropositioncardiac/cardiacmalformation \\
HPV & Oligoamnion \\
Depression & Skeletaldys plasia \\
Vascular disease & Dandy Walker \\
- & Cerebellar agenesis \\
- & Down syndrome \\
- & Twin-twin transfusion \\
- & Congenital malformation \\
(clubfoot, syndactyly, etc.)
\end{tabular}

action-reflection, encouraging them to overcome the difficulties and enabling the empowerment of being a high risk pregnant woman.

\section{DISCUSSION}

During pregnancy a woman goes through many situations and many of these lead pregnant women to be considered as being of greater or lesser risks, which may be exacerbated by social and obstetric factors. Factors identified in this study denote a pregnant woman profile that goes against institutional reality, focus of this study, where women have some level of education, are mostly in the company of someone of their choice, where they already had a previous pregnancy and possessed a belief that helps them during their journey, among others, favoring reflective moments and promoting better outcomes for the pregnant women.

To counter these moments of weakness are other noticeable changes in the profile of these women, who are increasingly seeking their independence, by becoming pregnant over the age of 30, studying longer, with a level of education that promotes sharing of knowledge, besides having a professional occupation, showing greater maturity in their behavior and decisions making. This new way of seeing the future, promotes a more secure 
and determined acting.

In line with the findings of this study are the notes made by [6] that highlight the main reasons for an advanced maternal age pregnancy, among these, the desire to invest in their academic training/studying and professional career; a choice for a later stable conjugal relationship; the formation of new unions; infertility problems among others.

On the other hand, the age of the women above 30 years is identified as a factor directly related to maternal mortality, particularly when associated with multigravida and other risk factors such as, low literacy and the absence of a companion during pregnancy. Therefore, women in this age group should be considered as highrisk pregnancies and will receive qualified prenatal care, tailored to their needs [7].

Despite their maturity, sentiment of insecurity, uncertainty, anxieties arise and are intensified at all times when confronted with new scenarios. However, these feelings are mitigated by faith and the belief of a higher Being, regardless of religious belief. It is this greater Being that gives strength and courage to face the difficulties during the course of the high risk prenatal [8].

Factors such as maturity of the studied pregnant women, linked to the faith that motivates them to keep going can be associated, in most cases, to the emotional support received from their companions, as well as their family, where the latter two, as faith, can provide for better emotional stability.

Although some pregnant women were not accompanied by their spouses during the high risk prenatal care, they were able to count on someone close to them, which proportionated a participatory presence in moments of reflection-action-reflection. For these ladies, it is important to build, in a collective space, their life stories, where they can share wishes and desires [9].

Several scientific studies, both domestic and international attest to the benefits of having the presence of a companion. Besides feeling more secure during the course of pregnancy, these women also demonstrated more confidence during labor [10].

However, we must consider that the absence of a significant other during the prenatal care is unfavorable to overcoming difficulties, not only during these times, but especially regarding the continuation of the dialog and on the return home, to the workplace and to the family.

Therefore, when the pregnant woman does not have a person of reference, it is important that the relationship between mother and nurse be even closer and stronger, as many of these women consider the nurse as being this particular provider of security and attention. Regardless of the situation, in the world of a high risk pregnancy, nursing consultations should be surrounded by a lot of dialogue, reflection and action throughout the whole time information is being shared.

Authors [11] point out to the importance of nurses in the prenatal care, as besides answering questions to the pregnant women and their companions during the meetings, this professional class has been contributing for the strengthening of a relationship of trust and closeness, as well as, providing comprehensive care with educational actions to the pregnant women, their unborn baby and companion.

Perhaps, a strong influence over the lack of companionship during the prenatal care of high risk in this study may be related to unplanned pregnancy. This factor also has strong relationship to the late beginning of prenatal care, in the second trimester of pregnancy, which is a period where these women begin to understand the physical and emotional changes typical of the gestational developing period, when they seek for health services to start the prenatal care.

In those situations where there was no planned pregnancy, risk factors for recurrence should be considered, especially when the mother is a teenager [12]. Thus, preventive care for a new pregnancy should be part of the educational and reflective actions during the high risk prenatal care.

For most pregnant women, the experienced risk in the pregnancy is something unique, not previously lived, that's because it is their first pregnancy or for previous pregnancy being within a favorable development and classified as low risk.

The experience of the current pregnancy of risk, was monitored, in almost all pregnant women, as outpatient, in other words, it was managed to keep the situation of fetal or maternal-fetal risk adequately controlled and stable, with no need for hospitalization at the maternity ward.

\section{FINAL CONSIDERATIONS}

In spite of the wide range of diagnoses identified during the course of pregnancy, we noticed that the most classification of obstetric risk was related to pathologies such depressive state and even depression. The latter is considered as the disease of the century, and when combined with hormonal and mood changes, it generates instability and disbelief of a promising future.

Based on our findings, we realized that the high risk pregnancy as a period that involves many factors, among them, social and obstetric that when connected, can compromise the gestation process for both the mother and the fetus.

In this sense, it is essential that the nurse, as an active professional during the prenatal care, promote a space that allows for dialog among all individuals within the pregnancy context, who are the pregnant woman, her companion and healthy professionals, by offering mo- 
ments of dialogue, reflections and actions that will progressively facilitate the overcoming of difficulties experienced during high risk pregnancies.

Among the study limitations, we can cite the absence of a spouse, for we could profile the couple and family better understand the organization as well as the lack of studies more specifically for high-risk pregnancies.

We suggest that further studies look in depth to the pregnant women's social and obstetric reality in their institution, and that they understand how to create a dialogue channel among professionals, pregnant women and their companions, so that they can better deal with issues that permeate a risky pregnancy, promoting actions to overcome difficulties experienced during the entire gestational period, that will help these individuals play an active role in the changes related to their own life story.

Among the recommendations, we believe that there is a need for a broader look by professionals who assist in high risk prenatal care, where the nurse should know the social and obstetric situation of each of the pregnant women and their companions, allowing them to correlate the main risk factors in an attempt to minimize them in the current pregnancy.

\section{REFERENCES}

[1] Brazil, Ministry of Health, Department of Health Policy (2000) Technical Manual of high risk pregnancy. 3rd Edition, Ministry of Health, Brasilia.

[2] Magalhaes, M.L., et al. (2006) Pregnancy in early and late adolescence: No difference in obstetric risks? Revista Brasileira de Ginecologia e Obstetrícia, 28, 446-452. http://www.scielo.br/scielo.php?script=sci_arttext\&pid=S 0100-72032006000800002\&lng=pt\&nrm=iso

[3] Brazil, the National Health Council (1996) Guidelines and rules for human research. Resolution No. 196, CNS, Brasilia.

[4] Brazil, Ministry of Health, Office of Strategic and Participative Management. Department Articulation Inter federativa (2012) Guidelines on indicators of agreeing on guidelines, objectives and goals in 2012. Ministry of Health, Brasilia.

[5] Walselfisz, J.J. (2012) Map of violence 2012 children and adolescents in Brazil. Brazil Cebela FLACSO, Rio de Janeiro.

[6] Gravena, A.A.F., et al. (2012) Perinatal outcome in pregnancies later. Revista da Escola de Enfermagem da USP, 46, 15-21.

[7] Soares, V.M.N., Schor, N. and Tavares, C.M. (2008) Lives risky: A reflection on the relationship between the number of pregnancies and maternal mortality. Brazilian Journal of Human Growth and Development, 18, 254-263. http://producao.usp.br/handle/BDPI/14320

[8] Baldwin, L.S.C., et al. (2011) Spirituality, coping and nursing: An integrative literature review. http://www.revista.ufpe.br/revistaenfermagem/index.php/ revista/article/viewFile/1737/pdf_456

[9] Basso, J.F. and Monticelli, M. (2010) Expectations, pregnant women and caregivers for humanized birth. Latin American Journal of Nursing, 18, 390-397.

[10] Lessa, R. and da Rose, A.H.V. (2010) Nursing and host: An importance of dialogic interaction in prenatal. http://dialnet.unirioja.es/servlet/articulo?codigo=3651897

[11] Cunha, M.A., Mamede, M.V.L., Dotto, M.G. and Mamede, F.V. (2009) Prenatal care: Essential skills performed by nurses. Escola Anna Nery Revista de Enfermagem, 13, 145-153.

[12] Silva, A.A., et al. (2013) Factors associated with recurrence of teenage pregnancy in a maternity hospital: Casecontrol study. Cad Public Health, Rio de Janeiro, 29, 496-506. 